\title{
Construindo Pontes: Inovações, Organizações e Estratégias como Abordagens Complementares
}

\author{
Ana Célia Castro \\ Coordenadora do Programa Internacional de Pós-graduação em Políticas de Desenvolvimento, \\ Instituiçōes e Estratégias (CPDA/UFRRJ e IE/UFRJ)
}

\section{Introdução}

O ponto de partida deste artigo-resenha é a seguinte definição concisa das instituições:" "As instituiçôes são sistemas duradouros de regras sociais estabelecidas e enraizadas que estruturam as interaçôes sociais" (Hodgson, 2004). Além disso, como assinalaram Chang e Evans, "nas sociedades modernas, elas [as instituiçōes] costumam encarnar-se em organizações competentemente coordenadas, com regras formais e com capacidade de impor sançōes coercitivas, como o governo ou as empresas" (Chang \& Evans, 2000). Os autores chamam a atenção para três dimensões do conceito: "Existe uma terceira visão das instituiçôes, que recebe relativamente pouca atenção dos economistas, mas, a nosso ver, é crucial. Essa visão entende as instituiçõos como não apenas habilitadoras ou cerceadoras, mas também como constitutivas. ${ }^{2}$ Isso porque todas as instituições têm uma dimensão simbólica e, por conseguinte, inculcam certos valores (ou uma visão de mundo) nas pessoas que vivem sob sua égide” (Chang \& Evans, 2000).

\footnotetext{
I Embora essa definição derive de Douglas North (1990), ela também é compatível, como foi assinalado pelo autor, com o antigo institutionalismo, como em Veblen (1919) e Commons (1931). Nesse sentido, ela é fundamental para a tese da "construção e travessia de pontes".

2 "Hodgson caracteriza essa visão como pressupondo uma 'causação reconstituidora descendente, das instituições para os indivíduos'", cf. Chang \& Evans, 2000.
} 
No que concerne à análise, parece fundamental distinguir a hipótese de um comportamento social anistórico do comportamento dependente da trajetória (conduta continuamente moldada pelas instituições preexistentes). Para o neoinstitucionalismo, a dimensão crucial parece ser o tipo de coordenação (ou governança) moldado pelo oportunismo e pela busca dos interesses pessoais. A coordenação é, sobretudo, uma questão de hierarquia. Quanto às abordagens institucionalista/evolucionária, argumentaremos que, no que diz respeito à coordenação, os conceitos de oportunismo, interesse pessoal, cooperação e rotinas organizacionais são todos inter-relacionados, mas a interação entre as instituições, a inovação e a estratégia organizacional deve ser o cerne da análise e da formulação das políticas do setor. ${ }^{3}$

A primeira parte do artigo-resenha introduz as perspectivas neo-institucionalistas na análise de casos de agronegócio latino-americanos. Pretende-se mostrar que essa abordagem produz uma análise muito particular (e, em certo sentido, limitada) das estratégias empresariais. A segunda parte apresenta um exemplo específico de uma abordagem institucionalista/evolucionária centrada nas organizações e em suas estratégias. Nela se espera demonstrar que a visão baseada nos recursos, para fins de estudo das estratégias das empresas, não pode ser compreendida sem referência a uma análise schumpeteriana da concorrência e da inovação. A terceira e última parte resume os argumentos e propõe algumas conclusões.

\section{Formas de governança e coordenação na economia neo-institucionalista}

O reconhecimento da incerteza como traço inerente aos mercados, ao lado de seu funcionamento imperfeito, da existência de informaçôes incompletas, da assimetria entre seus agentes e da possibilidade do risco moral no cumprimento dos contratos, em suma, a aceitação das alternativas limitadas de que dependem os mercados, tudo isso levou à consideração de um conjunto de custos (de transação, de produção, etc.) que entram nas estimativas econômicas empresariais. A economia dos custos de transação é uma generalização da teoria

3 Essa interpretação original de formas de coordenação muito diferentes nas organizações deve-se ao material de ensino de Benjamin Coriat no Programa de Pós-graduação em Políticas de Desenvolvimento, Instituições e Estratégias. 
da empresa que leva em conta, simultaneamente, os dois tipos de custos, e permite uma explicação das formas de coordenação interna da companhia não relacionada com os preços: mecanismos distintos de coordenação interna que refletem sua hierarquia, suas formas de gestão e seus incentivos à produção e à produtividade, entre outros.

Os modelos baseados na Economia dos Custos de Transação (ECT) consideram os atributos da transação e os custos institucionais como variáveis exógenas, além de levar em conta os pressupostos da racionalidade limitada e da possibilidade do comportamento oportunista por parte dos agentes (com base, entre outras coisas, na existência de informações assimétricas). Williamson destaca três níveis de racionalidade: a "forma forte", que explica as condutas maximizadoras dos agentes; a racionalidade limitada (ou semiforte), conceito desenvolvido por Simon (1976) - os indivíduos são intencionalmente racionais, ainda que de maneira limitada; - e a "racionalidade orgânica", que é a racionalidade fraca (Williamson, 1985:44). A variável importante é o modo de organizar a produção que minimize os custos totais: a hierarquia ou organização interna (integração vertical das etapas), a implementação de vários tipos de controle e o mercado.

Sem dúvida, ao lado das formas opostas do mercado e da empresa, as economias contemporâneas contêm uma ampla variedade de formas intermediárias de coordenação. Claude Ménard (1997) identifica essas formas como híbridos: a hierarquia das grandes empresas: a quase integração vertical de um conjunto de subcontratantes; as redes de franquias; as alianças estratégicas; as joint ventures produtivas, tecnológicas e comerciais; e os consórcios e relaçóes contratuais.

Nesse contexto, segundo a ECT, essas formas distintas de coordenação provêm da dificuldade de firmar contratos completos que consigam especificar todas as obrigações das partes intervenientes. Em vista disso, existem custos anteriores à assinatura dos contratos, ligados à necessidade de obter informações sobre os bens, os mercados e os parceiros potenciais, bem como custos ligados à própria negociação dos contratos e custos derivados da necessidade de controlar e supervisionar os acordos contratuais. ${ }^{4}$

\footnotetext{
4 São os seguintes os atributos considerados básicos nas transações: freqüência, incerteza e especificidade dos ativos tecnicamente associados à transação, que podem dever-se a várias razões, como a localização dos investimentos, a especialização de um investimento na produção de determinado produto para um cliente, etc. (Williamson, 1985; Zylbersztajn, 1996).
} 
A visão de Williamson enfatiza as relações contratuais e diverge um pouco dos "direitos de propriedade" de Coase (1937). Assim como North (1990), Williamson (1985) reconhece que as instituições compõem a base importante da teoria ("as instituições como conjunto de restrições e normas", as regras do jogo da sociedade). No entanto, é claro que as instituições não representam apenas restrições, mas possuem, por sua vez, a capacidade de conferir maior estabilidade ao sistema e de permitir o desenvolvimento das próprias organizações.

A abordagem de Williamson deixa sem resposta a questão de quais seriam as estruturas de governança mais eficientes, conforme suas características:

"Embora os mercados fossem comumente vistos como o principal meio de realizar a coordenação, Coase insistiu em que as empresas freqüentemente os superavam no desempenho dessas mesmas funçōes. Em vez de considerar as fronteiras das empresas como tecnologicamente determinadas, Coase propôs que as empresas e os mercados fossem considerados formas alternativas de organização econômica (1952, p. 33). Assim, organizar as transaçôes dentro da empresa (hierarquicamente) ou entre empresas autônomas (num mercado) seria uma decisão variável. A modalidade adotada dependeria dos custos de transação pertinentes a cada uma delas." (Williamson, 1985:4)

Ao analisar essas formas institucionais, a teoria concentra-se nas relações contratuais, mais especificamente nos mecanismos contratuais de governança. Esse esquema aponta para uma interação no meio institucional que estabelece os parâmetros da governança e, por sua vez, é um reflexo dos atributos comportamentais da conduta individual. Mas existem elementos de retroalimentação.

A relação entre indivíduos e estruturas de governança poderia ser caracterizada como uma relação que faz certas suposições próprias do pensamento do autor. Consideremos, em primeiro lugar, a premissa de Simon (1976) sobre a racionalidade limitada. Para Simon, a limitação da racionalidade é explicável pela limitação dos processos cognitivos. Para o neo-institucionalismo, cabe acrescentar outra premissa a essa limitação da racionalidade - a dos comportamentos oportunistas. Essa idéia é central na teoria, tanto no que concerne a implicações do tipo das indicadas por Coase (a necessidade de organizar a empresa para protegê-la dos comportamentos oportunistas) quanto no tocante à importância 
dos contratos, que têm a mesma função de reduzir os custos de transação. O oportunismo pode assumir três formas distintas: o "ruidoso", o sutil e o natural. O oportunismo "ruidoso" é explícito. É a forma sutil que tem uma dimensão estratégica, que viria a ser adotada por Williamson (1985): a busca do "interesse pessoal com astúcia".

O segundo aspecto central é a proposição de que as estruturas de governança têm vida própria, a qual inclui exigências de controle, formas hierárquicas, a questão da identidade e da capacidade, a burocratização (uma das tarefas da economia dos custos de transação é explicar as falhas burocráticas em termos institucionais comparativos) e a adaptação - um dos principais problemas da organização econômica. Por último, cada tipo genérico de governança (de mercado, híbrida e hierárquica) difere substancialmente em sua capacidade de se adaptar de maneira autônoma e cooperativa. Em outras palavras, a teoria espera que os atributos das transações e sua freqüência definam formas distintas de governança.

O Quadro 1 resume as proposições da teoria: as transações com baixo grau de especificidade ocorrem no mercado; as altamente específicas ou idiossincráticas (de alta freqüência) ocorrem através da empresa; no caso de transações com grau médio e alto de especificidade (porém baixa freqüência), faz-se necessária a contribuição de uma estrutura de governança do tipo "aparelho regulador" para dissipar as controvérsias. Por fim, no tocante às transaçôes com grau médio de especificidade, mas de alta freqüência, a teoria prevê a existência de contratos bilaterais ou de relaçôes contratuais mais duradouras.

\section{QUADRO 1}

Relações entre as características e a freqüência das transações e as estruturas correspondentes de governança

$\begin{array}{lccc}\begin{array}{l}\text { Grau de especificidade / } \\ \text { freqüência da transação }\end{array} & \text { Não específica } & \text { Mista } & \begin{array}{c}\text { Específica ou } \\ \text { idiossincrática }\end{array} \\ \text { Ocasional } & \text { Regida pelo mercado } & \text { Governança trilateral } & \text { Governança trilateral } \\ \text { Reiterada } & \text { Regida pelo mercado } & \text { Governança bilateral } & \text { Empresa }\end{array}$

Fonte: elaboração própria. 
Reconhece-se que a economia neo-institucionalista, com seu foco central nas formas de governança, não leva suficientemente em conta o meio institucional e os aspectos culturais que estão em processo contínuo de incorporação pelas organizaçôes. A teoria recomenda a "economia dos custos de transação" como o principal fator para explicar como ocorre "a escolha da forma de organização". Portanto, a transação converte-se na unidade de análise da teoria. Um problema típico é a decisão de fazer ou não a integração vertical ("produzir ou comprar"). Em termos mais gerais, esse problema é redefinido como sendo o de criar estruturas de governança baseadas em relações contratuais. Tipicamente, o resultado teórico visado é representado da seguinte maneira: "as transações, que diferem em termos de seus atributos, estão alinhadas com estruturas de governança que possuem custos e eficiência diferentes, de maneira discriminatória ou em termos de economizar os custos de transação" (Zylbersztajn, 1996).

O processo contratual caracteriza-se por contratos de longo prazo em que há interaçôes freqüentes e prolongadas entre as partes, com a presença de ativos específicos e um limite da capacidade preditiva dos contratos ("contratos incompletos"). Isso requer uma combinação da especificação prévia detalhada das garantias e incentivos destinados a minimizar os riscos (risco moral) com mecanismos de governança que lidem com as deficiências contratuais constatadas a posteriori. Do ponto de vista da interação estratégica, o oportunismo nas relações contratuais só pode ser mantido por uma combinação de ameaças "dignas de crédito" e "compromissos dignos de crédito", o que envolve investimentos, em geral com custos não recuperáveis (sunk), dada a especificidade dos ativos. Essas salvaguardas implicam custos, mas podem viabilizar transações que jamais ocorreriam de outra maneira. Desse ponto em diante, o lucro é obtido mediante a eficiência de alocação que possa resultar desses mecanismos de governança e de salvaguardas estrategicamente confiáveis.

No caso específico dos sistemas agroalimentares (SAGs), ${ }^{5}$ pode haver coexistência de uma multiplicidade de formas de funcionamento, que são combina-

\footnotetext{
5 O conceito de sistema agroalimentar refere-se ao conjunto de subsistemas relacionados com as atividades agroindustriais e agroalimentares numa economia nacional. Visto que os processos de globalização reuniram os sistemas agroalimentares do planeta, alguns autores falam num sistema agroalimentar mundial, tanto em termos de relações comerciais (importação e exportação) quanto em termos da difusão de novos produtos e novos processos inovadores, bem como da generalização de certas normas, instituições e convenções compartilhadas no interior do sistema. Além dos setores, indústrias, mercados e empresas, o conceito de sistema agroalimentar inclui as instituições que os regulam e que condicionam sua dinâmica. Esse conceito é mais abrangente que os de complexo agroindustrial, cadeias agroalimentares, filière, cluster, agronegócio, pólos agrícolas ou arranjos produtivos locais, entre outros. Cada um desses conceitos tem uma historicidade e um significado particulares, cujo exame não é objeto deste artigo-resenha.Ver o primeiro capítulo de Ana Célia Castro e Graciela Guttman, Manual de Cadenas Agroalimentarias, FAO (2002).
} 
ções complexas de relações de mercado, hierarquias verticais, relações de confiança e diversas formas de relações contratuais. ${ }^{6}$ A predominância de uma ou de outra depende das características institucionais e organizacionais de cada SAG.

Os aspectos centrais dos estudos sobre a dinâmica dos SAGs consistem em compreender em que condições as diferentes formas de coordenação ou governança se impõem e que elementos entram em sua determinação. Estes podem referir-se a diferentes questôes: as condições técnicas da produção; as características da demanda; seu grau de internacionalização; a natureza das relações de produção e das relações com o sistema de crédito; o grau de diferenciação dos produtos; as formas assumidas pela competência interempresarial e a morfologia do mercado.

As formas de organização e regulação setorial e macroeconômica das instituiçôes fornecem elementos que ajudam a explicar as várias modalidades de coordenação passíveis de serem encontradas nos sistemas agroalimentares. Dispositivos institucionais compõem o conjunto de instituições que produzem normas, processos e intervenções que estruturam e dirigem a atividade econômica. As regras do jogo (intervenção estatal, livre mercado, várias formas de acordos ou coordenação privados), as técnicas de produção e as preferências do consumidor definem o espaço de reprodução dos SAGs. As crises, por sua vez, são momentos de reformulação de normas institucionais que promovem a adaptação dos SAGs à concorrência internacional e às mudanças tecnológicas rápidas (Boyer, 1988). ${ }^{7}$

Com respeito aos SAGs na América Latina, estudos recentes levaram em conta as múltiplas formas de coordenação registradas nessas atividades (ver Schejtman, 1998 e Teubal, 1995). O desenvolvimento de relaçóes contratuais no agronegócio latino-americano é uma modalidade em expansão, impulsionada pelas formas modernas de competência presentes nos SAGs (demanda crescente de qualidade e diferenciação dos produtos, aumento da freqüência e da segurança do fornecimento a grandes empresas, grandes mudanças tecnológicas) e pelas incertezas associadas a essa produção (riscos ligados às condições do tem-

6 O caráter incisivo da divisão do trabalho na agricultura está na origem dos níveis maiores de produtividade alcançados graças à maior especialização, e aumenta os riscos técnicos e a insegurança econômica. Por isso, há necessidade de uma coordenação dos diversos agentes produtivos, a fim de garantir a boa circulação das informações por um custo mais baixo.

7 Convém assinalar que, em alguns SAGs, em determinadas circunstâncias, os compromissos institucionais podem bloquear o desenvolvimento das forças produtivas para preservar as rendas de monopólio, determinando a orientação e a rapidez do intercâmbio técnico (Boyer, 1988). 
po, pragas, epidemias). ${ }^{8}$ De acordo com os pressupostos da ECT, o objetivo central dessas formas de coordenação vertical é minimizar os custos totais de produção e de transação, a fim de obter maior eficiência. Sem negar as vantagens que todas as partes extraem da maior coordenação das atividades obtida graças a essas relações, ${ }^{9}$ a relação contratual dos SAGs pode ser uma estratégia para controlar os processos produtivos da agricultura e a apropriação, por parte do capital industrial, financeiro ou comercial, dos maiores níveis de produtividade gerados pela especialização e pela mudança tecnológica. Assim, o contrato aparece como uma manifestação da contratação da capacidade econômica do produtor rural pela empresa e como um meio de diferenciação social dos agricultores.

Isso ocorre, em particular, no contexto das forças econômicas assimétricas decorrentes da fragilidade e da dispersão dos produtores rurais, da concentração oligopsonista das indústrias e da distribuição de alimentos, e da falta de instituições que efetuem o controle e a mediação dos conflitos. Convém observar que a ECT continua a influenciar os conceitos da teoria das organizações. Através desses contratos, as empresas industriais e comerciais conseguem desenvolver fornecedores especializados e semicativos, bem como gerar margens de lucro maiores, aumentando a velocidade de giro do capital industrial e evitando a mobilização de grandes somas na produção primária.

O Quadro 2 apresenta um resumo do tipo de análise de contratos feito com essa abordagem. O esquema foi elaborado por Loader (1995), que avaliou contratos entre supermercados ingleses e exportadores de batatas. Inicialmente, a tabela se propõe descrever detalhadamente as transaçóes, concentrando-se em suas características de recursos, exposição a riscos e especificidade dos ativos. Loader assinala a existência de uma assimetria na transação, conforme ela seja vista por um ou outro agente. As formas distintas de governança (mercado, contrato ou hierarquia) são comparadas com as características específicas das transaçōes, fazendo-se uma tentativa de verificar se os resultados são previsíveis pela teoria.

8 Os contratos podem ser de vários tipos: formais ou informais, apenas de compra e venda, ou incorporando assistência técnica e/ou fornecimento de matérias-primas, e/ou crédito e/ou consultoria administrativa (ver resumos de caso em Schejtman, 1998).

9 Para o agricultor, as vantagens provêm da colocação segura dos produtos e do acesso a tecnologias modernas e à assessoria técnica; na indústria, os contratos permitem o controle e a garantia da quantidade e qualidade das matériasprimas, induzem ao desenvolvimento tecnológico necessário para atender às exigências da demanda e transferem os riscos ligados às condições do tempo para o produtor rural. 


\begin{tabular}{|c|c|c|c|}
\hline Especificidade dos ativos & Baixa & Média & Alta \\
\hline Baixa & Mercado & Mercado & Mercado \\
\hline Média & Contrato & $\begin{array}{l}\text { Contrato ou } \\
\text { integração vertical }\end{array}$ & $\begin{array}{l}\text { Contrato ou } \\
\text { integração vertical }\end{array}$ \\
\hline Alta & Contrato & $\begin{array}{c}\text { Contrato ou } \\
\text { integração vertical }\end{array}$ & Integração vertical \\
\hline
\end{tabular}

Fonte: Zylbersztajn e Fava Neves (2000).

Mesmo com respeito à análise de contratos, Milgrom e Roberts (1992) frisam a importância da "coordenação", ou do modo de organizar a produção de bens e serviços. Esse esquema baseia-se na idéia dos benefícios da especialização em cada etapa da cadeia produtiva e presume que, quando há "cooperação" entre os atores, há uma produção eficiente. Segundo King (1982), pode-se obter a "coordenação" mediante a aquisição de matéria-prima no mercado aberto, por meio da integração vertical ou pela implementação de acordos contratuais de curto ou longo prazo entre as empresas. Cada uma dessas modalidades tem custos diferentes, donde é presumível que se privilegie a forma de coordenação que minimize os custos de transação. Os contratos oferecem vantagens, tais como a redução da incerteza da coordenação, quando as compras ocorrem no mercado aberto, e a possibilidade de exercer algum controle sobre os processos de produção. Grosso modo, as empresas que adquirem matérias-primas assumem obrigações (como prestar assistência técnica, fornecer insumos, etc.). Para o produtor (do ponto de vista dos custos/benefícios), presume-se que a produção e/ou a comercialização em moldes contratuais facilite seu acesso aos insumos tecnológicos e estabilize sua renda, embora também inclua uma perda de autonomia no processo decisório.

Como vimos, há uma importância inegável na análise dos contratos no sistema agroalimentar. No tocante a alguns efeitos, seria até aceitável que as 
unidades (subsistemas, empresas, conglomerados, etc.) desse sistema fossem entendidas como um nexus de contratos. Entretanto, essa visão mais faz ocultar do que revelar, no que concerne a outras dimensóes do sistema agroalimentar para as quais gostaríamos de chamar a atenção. Elas nos parecem centrais: a introdução de inovações tecnológicas e a dimensão estratégica. Também procuraremos questionar as hipóteses do oportunismo dos agentes e a especificidade dos ativos como explicação básica para a existência das empresas. Além disso, temos a convicção de que a hipótese das estruturas híbridas de mercado, introduzida por Claude Ménard, como vimos, insere uma cunha (ou produz uma rachadura importante) no edifício teórico neo-institucionalista. Esse ponto será desenvolvido na conclusão. ${ }^{10}$

\section{Combinando as abordagens institucionalista/evolucionária com a análise das estratégias empresariais}

\section{Os conceitos de instituição, organização e mercado nas abordagens institucionalista e evolucionária}

Para construir uma compreensão ampla das instituições, é preciso ir além da postura institucionalista tradicional, que define as instituições como "restrições" ou regras do jogo que condicionam o comportamento e a interação social dos indivíduos: elas fazem parte das restrições formais e informais (convenções, códigos de conduta, etc.), determinam as regularidades, reduzem as incertezas e proporcionam uma estrutura para o funcionamento da economia e da sociedade (North, 1990).

No entanto, também é preciso ir além da visão funcionalista das instituições, na qual estas são instrumentos eficientes que permitem a consecução de alguns objetivos que exigem coordenação individual, de acordo com os autores da Nova Economia Institucional (NEI). Ou até ir além da visão keynesiana de que as instituições são necessárias para garantir o cumprimento dos contratos.

É necessário ainda ir além da perspectiva instrumentalista, que acredita

\footnotetext{
${ }^{10}$ Este texto já tinha sido redigido quando recebi o artigo de Geoffrey Hodgson, "Opportunism is Not the Only Reason Why Firms Exist: Why an Explanatory Emphasis on Opportunism May Mislead Management Strategy", in Industrial and Corporate Change, v.13, n.2, p.401-418, 2004. A tese que pretendo desenvolver segue a mesma direção dos argumentos elaborados por Hodgson.
} 
que as instituições se formam e se modificam para refletir os interesses exogenamente definidos dos mais poderosos, ou que são constitutivas dos interesses e visões de mundo dos agentes econômicos, como na óptica da economia política.

Todos esses elementos estão presentes nas definições das instituições - como restrições, como instrumentos eficientes e como reflexo de interesses. Mas há, sem dúvida, uma quarta visão das instituições, que as percebe como "constitutivas", uma vez que elas possuem uma dimensão simbólica (cultural) e, portanto, disseminam alguns valores ou crenças comuns entre os diferentes atores. Como resultado, os valores incorporados são internalizados nessas instituiçōes. "É nosso propósito ir além dessa visão 'rala' das instituições e chegar a uma visão 'densa', que reconheça o papel fundamental da cultura e das idéias e o papel constitutivo das instituições na moldagem das maneiras pelas quais os grupos e indivíduos definem suas preferências" (Chang \& Evans, 2000).

Poderíamos acrescentar uma definição sintética: "As instituições são sistemas duradouros de normas sociais estabelecidas e enraizadas que estruturam as interaçôes sociais" (Hodgson, 2004). Portanto, a mudança institucional requer a mudança das visões de mundo que estão inevitavelmente por trás da estrutura das instituições: a mudança institucional - ou a "nova institucionalização" (as instituiçôes se modificam durante as fases de ruptura, ou principalmente para se adequar ao meio mutável) - mostra-nos como as sociedades evoluem no tempo e, portanto, constitui a chave para compreendermos a mudança e a ação social.

\section{Instituições e organizações}

De acordo com Douglas North (1990), as instituições são o conjunto das regras do jogo, mas as regras devem ser distinguidas dos jogadores. As organizações são jogadores que, por meio de sua capacidade, suas estratégias e sua coordenação, também exercem influência na criação ou na evolução das próprias regras do jogo, ou, em outras palavras, nas instituições já existentes e/ou novas.

Hodgson fornece-nos outros esclarecimentos: "Qual é a diferença entre uma organização e uma instituição? North escreveu: 'Se as instituiçôes são as regras do jogo, as organizaçōes e seus empresários são os jogadores.' Algumas pessoas interpretaram essa afirmação de North como significando que as organizaçōes em si não são instituiçôes. Mas não é realmente isso que ele diz. North simplesmente afirma 
seu interesse primordial nos sistemas econômicos, e não no funcionamento interno de organizaçôes individualmente consideradas. Além disso, de modo correspondente a este autor, ele deixou clara a sua crença em que as organizaçôes também são instituiçôes. Ele admite que as próprias organizaçôes têm jogadores e sistemas de regras internos, donde, por implicação, constituem um tipo especial de instituição." 1 Em suma, as organizações também são instituições, e seu processo de institucionalização não está garantido (Selznick, 1997). Em outras palavras, nem todas as organizações ou empresas se institucionalizam. Embora as organizaçoes também sejam instituições, é preciso levar em conta que as primeiras são entidades capazes de uma dimensão estratégica.

$\mathrm{Na}$ famosa introdução de seu livro Organizations, March e Simon definem as organizaçōes em termos dos elementos que as constituem: a dimensão dos interesses, a dimensão da informação e a dimensão do conhecimento ou do aprendizado. Para que uma organização integre suas três dimensões constitutivas, a coordenação é fundamental. Para o neo-institucionalismo, a hierarquia é a principal dimensão da coordenação. Em termos mais gerais, porém, ela poderia ser resumida como as formas de coordenação dentro das organizações - não apenas a hierarquia, mas sobretudo a eficiência X ( $x$-efficiency), os incentivos, as punições, as rotinas organizacionais, a cultura empresarial e a cooperação. $^{12}$

A análise das organizações (mesmo de natureza diferente) - empresas, organizações do setor público, inclusive as que geram novas tecnologias, formulam e respondem pelas políticas públicas voltadas para os setores agrícola, industrial e comercial, organizações de ensino, pesquisa, sociais etc. $-{ }^{13}$ leva em conta seus padrões comportamentais: normas, heurísticas bem-sucedidas, rotinas (Nelson \& Winter, 1982) e cultura organizacional. Essas análises servem para identificar os pontos fortes e fracos das organizaçóes e para indicar as necessidades de mudança institucional/organizacional. ${ }^{14}$

${ }^{11}$ Hodgson, 2003. Quanto a esse tema, ver o clássico artigo de Selznick $(1957,1997)$ que chama a atenção para a competência distintiva das empresas, base de seu processo de institucionalização. Ver Foss (1997) p. 23.

12 Ver também H. Liebenstein, X-Efficiency Theory and Economic Development, 1978. No que concerne às diferentes formas de coordenação, Benjamin Coriat é responsável por essa visão integrada.

${ }^{13}$ Entendemos que o próprio mercado é uma instituição, provida de um conjunto de normas, restrições, etc. Essa concepção institucional do mercado opõe-se à que o compreende como o locus da livre atuação das forças econômicas e o ponto de encontro entre a oferta e a procura.

${ }^{14}$ Smith (2001) discorreu sobre o caso da reforma das instituições públicas envolvidas na oferta de serviços (pesquisa, extensão, crédito, comercialização, serviços veterinários e administração de recursos hídricos) ao setor agrícola. 
As organizações se definem por seus objetivos (ou, mais exatamente, por suas estratégias). A dimensão estratégica está indissociavelmente ligada ao conceito das organizações e de suas aptidões. Sem essa dimensão estratégica, não é realmente possível compreender a natureza específica das organizações. Obviamente, as mudanças institucionais, o contexto ou a demanda ambiental enfrentados por elas também modifica suas estratégias, a fim de readaptá-las a novas situações. A eficiência estratégica das organizações é medida através da competitividade.

O estudo das organizaçôes leva a um debate interessante a respeito de seu funcionamento e/ou coordenação. As hierarquias (empresas) e os mercados são alternativas opostas para a teoria. Como vimos, autores como Ménard (1997) assinalam a importância das formas híbridas de organização, a exemplo das cadeias de empresas e franquias, entre outras. Os arranjos entre empresas (transações que ocorrem fora do mercado) exigem a cooperação como requisito. Assim, a cooperação, e não o oportunismo, pode caracterizar melhor as relaçóes entre diferentes organizações e entre indivíduos. É importante salientar que a cooperação de que estamos falando, neste caso, não é resultante de interaçóes estratégicas (como na teoria dos jogos), ${ }^{15}$ mas consiste numa cooperação genuína.

O funcionamento das instituições/organizações depende, portanto, de hipóteses comportamentais concernentes aos indivíduos. Os conceitos já incorporados pelo neo-institucionalismo - oportunismo, racionalidade limitada, escolha adversa e risco moral -, ou, em termos gerais, os conceitos de interesse pessoal predominante ou de comportamentos característicos de busca de rendimentos, limitariam as possibilidades da mudança institucional e o aumento das opções estratégicas dos agentes. Os avanços da teoria dos jogos, agora baseados na visão da psicologia cognitiva, ${ }^{16}$ apontam para a cooperação como uma propriedade que emerge da interação social reiterada. Em outras palavras, a cooperação é um requisito da repetição da interação social entre os indivíduos no âmbito das organizações.

As hipóteses concernentes ao comportamento humano são cruciais, portanto, e influenciam as estratégias das organizações e sua coordenação. Além disso, devemos distinguir entre a hipótese de comportamentos sociais anistóricos

\footnotetext{
${ }^{15} \mathrm{Na}$ teoria dos jogos, como sabemos, a cooperação resulta de comportamentos racionais, guiados pelo interesse pessoal.

${ }^{16}$ A psicologia cognitiva estuda os processos cognitivos implicados na aprendizagem e na adaptação das espécies ao meio ambiente. Ver Barkow et al., 1992.
} 
e os comportamentos dependentes da trajetória (isto é, comportamentos moldados de algum modo pelas instituições preexistentes). De interesse preponderante para o neo-institucionalismo, como vimos, é a coordenação das organizações, e não suas estratégias. Assim, a questão da coordenação, particularmente dentro da organização, depende de hipóteses acerca do oportunismo, do interesse pessoal, da cooperação e da rotina organizacional. A hierarquia nas empresas significa autoridade, como mecanismos de atos compulsórios. As formas de governança que assumem arranjos organizacionais distintos tornam-se mais complexas em função da existência de formas híbridas e de associações entre empresas, questionando o papel da autoridade hierárquica nas empresas e organizações.

\section{A perspectiva baseada em recursos como abordagem principal das Escolas de Administração}

O meio em que se situam as empresas sempre foi considerado de extrema importância para determinar as estratégias empresariais. Nos modelos de estrutura/conduta/desempenho (ampliados de modo a incluir o modelo de M. Porter), a estrutura do mercado seria quase determinante na definição das estratégias. $\mathrm{Na}$ hipótese de uma relativa estabilidade do meio, os padróes comportamentais e setoriais de competência também seriam estáveis. A empresa não se caracterizaria por ter uma estratégia única: ou ela se adaptaria ao ambiente e aos padrões de competência setorial, ou estaria simplesmente condenada ao fracasso. A conduta e o desempenho seriam determinados pela estrutura, que definiria o padrão de competência setorial, e, em contraste, as características e/ou os recursos da empresa seriam desvalorizados. O conceito de Porter sobre as cinco forças foi acrescentado como um avanço em relação ao conhecimento empresarial do ambiente.

Num meio permanentemente mutável, no qual a instabilidade e o risco são características estruturais, convém levar a sério a hipótese de que o ambiente seja considerado a partir da visão que o empresário tem das possibilidades e limitações de sua empresa. A rigor, sem essa hipótese, inicialmente elaborada por Edith Penrose em 1957, ${ }^{17}$ as empresas seriam paralisadas pela incerteza do ambiente.

\footnotetext{
17 Conforme a versão apresentada em Foss, 1997.
} 
A grande contribuição dos autores identificados com a perspectiva baseada em recursos, especialmente as contribuições clássicas de Penrose (1997), Chandler (1997), Nelson e Winter (1982) e Nelson (1997), não teve como preocupação central uma análise das estratégias empresariais. Por haverem privilegiado a interação das empresas com o meio, esses autores concentraram-se na coleção singular dos recursos da firma. Assim, a análise do crescimento de uma empresa começa por uma análise de seus recursos, e não do meio em que ela atua, e só depois passa a uma discussão dos efeitos de certas condições ambientais em suas estratégias. A hipótese de Penrose é que, primeiro, o meio é afetado pela ação das próprias empresas, e depois modifica suas reações, num processo interativo de retroalimentação.

A questão estratégica ${ }^{18}$ refere-se à aquisição e manutenção de uma vantagem competitiva. Visto que as empresas são diferentes, considerando-se sua base heterogênea de recursos, elas competem no mercado calcando-se em estratégias diferenciadas. Não basta que os recursos (ou serviços) sejam únicos e que as estratégias empresariais sejam diferentes. É necessário que as diferenças entre elas se mantenham ao longo do tempo, que não sejam imitadas, e que existam algumas barreiras protetoras para salvaguardar as rendas diferenciadas que são geradas pelo processo competitivo. Assim, a VBR (visão baseada em recursos) desponta nas escolas de administração (particularmente na Harvard Business School) como a abordagem dominante em qualquer discussão das estratégias empresariais, firmemente ancorada na visão dos economistas da teoria da empresa. Os recursos e serviços podem ser tangíveis, como a capacidade produtiva física, e intangíveis, como os elementos que compõem a organização e a cultura interna da empresa. Não há dúvida de que o recurso intangível mais precioso é o conhecimento, pois ele confere às empresas uma certa capacidade (ver Quadro 3). Essa capacidade, que diferencia uma firma de todas as demais, é sua competência central (ou nuclear) (Prahalad \& Hamel, 1997).

Ao assinalar a importância da capacidade, Penrose (1997) observa que esses serviços são obtidos através de um recurso caracterizado por não ser um insumo da firma: sua capacidade organizacional. Esta pode ser definida como uma combinação de recursos, pessoas, valores e processos nas organizações. Inclui a capacidade de produzir por um custo baixo (eficiência) e a de saber escolher o

\footnotetext{
18 As principais referências sobre a estratégia são os livros clássicos de Mintzberg e Quinn (1998), e de Guemawat et al. (1999).
} 


\section{QUADRO 3 \\ Recursos e capacidade}

Conceito de recursos. Embora seus proponentes façam um uso consideravelmente literal do termo, os recursos implicam, em termos muito latos, algo que pode ser tido como um ponto forte ou fraco da empresa. A utilização prática da VBR exigiu uma definição mais exata do que seriam os "recursos". A proposição central é que um recurso é um atributo da empresa que não pode ser alterado a curto prazo. Os recursos podem assumir várias formas, desde as características comuns da produção até ativos altamente diferenciados. Mas sua natureza deve sempre ser percebida como um estoque, em contraposição às atividades empresariais, pela qual escoa o fluxo da renda, dos investimentos e das despesas. Os recursos podem ser definidos como tangíveis e intangíveis. Mais fáceis de avaliar, os recursos tangíveis são os ativos visíveis da firma. Incluem imóveis, instalações e estoques de matéria-prima, entre outras coisas. Tipicamente (por ser possível comprá-los), eles pouco contribuem para as vantagens competitivas. Existem exceções: uma cadeia de empresas bem instalada e bem situada pode representar uma fonte inestimável de vantagens competitivas em relação aos concorrentes; outro exemplo seria a propriedade exclusiva dos direitos sobre um rico filão de metais preciosos.

Os recursos intangiveis incluem uma reserva de ativos como a marca comercial, a cultura, o conhecimento tecnológico, as patentes e a aprendizagem e experiência acumuladas, entre outros. Esses recursos têm um papel importante, seja respaldando (ou enfraquecendo) as posições competitivas, seja valorizando (ou desvalorizando) a empresa. Além disso, têm freqüentemente a vantagem de não se deteriorar nem ser consumidos com o correr do tempo. Ao contrário, seu uso inteligente pode torná-los mais fortes e mais eficazes. Este último ponto (a capacidade da empresa na utilização de seus recursos) dá origem a um conceito associado a um tipo "especial" de recurso intangível: a capacidade organizacional da empresa. (Castro \& Proença, 2001) 
que fazer (efetividade). Inclui também a capacidade de melhorar o desempenho da empresa, seja em termos de novos produtos ou serviços, seja de novos processos de produção, vendas, financiamento ou propaganda etc. Essas aptidões, como observou Penrose, são aspectos fundamentais na determinação da vantagem competitiva das firmas.

O objeto da análise de Penrose (1997) é o crescimento da empresa. Esse crescimento revela-se uma conseqüência, não necessariamente uma intenção, gerada pelas forças internas da companhia e decorrente da melhor utilização que os empresários saibam fazer dos serviços dos recursos produtivos. ${ }^{19} \mathrm{O}$ limite do crescimento é "empresarial": a firma não consegue encontrar disponíveis no mercado, por um preço constante, os serviços produtivos que permitiriam um crescimento contínuo, inclusive serviços "organizacionais".

Embora a capacidade administrativa restrinja o crescimento da empresa, essa capacidade continua a ser permanentemente gerada dentro dela. Há um impulso para o crescimento da empresa e para a diversificação de suas atividades: à medida que a firma cresce, os recursos que permitirão seu próprio crescimento futuro também se expandem, necessariamente. A expansão das bases de operação da empresa cria um excesso de capacidade que força seu crescimento futuro.

Mas há um subconjunto de aptidôes que responde pela continuidade do crescimento da empresa. A capacidade dinâmica é a competência que permite à empresa criar novos produtos e processos e fazer frente às circunstâncias mutáveis do mercado. A competência e a capacidade são recursos intangíveis, porque, tipicamente, precisam ser construídos e não podem ser comprados. Tais aptidões não devem ser confundidas com o conceito de cultura administrativa. A cultura empresarial refere-se aos valores e crenças de uma companhia (seus empregados, dirigentes, etc.). Para esse conceito, a cultura é de fato o sistema de governança da firma, responsável pela mediação entre o comportamento dos indivíduos e a economia dos custos de coordenação. ${ }^{20}$

A preservação da posição competitiva calcada nas estratégias da empresa é assegurada pela capacidade de manutenção da liderança no mercado. A capacitação

\footnotetext{
19 Os limites do crescimento derivam da capacidade administrativa restrita de expandir os serviços que esses fatores proporcionariam à empresa.

20 Esse conceito, introduzido por David Teece em sua análise da empresa, ajuda a compreender outros processos organizacionais e empresariais - integração, aprendizagem, reconfiguração e transformação, posição (localização), capacidade de imposição ("avaliação"), reprodutibilidade e imitabilidade do processo organizacional.
} 
dinâmica mencionada por Teece (1998) - a aptidão para sentir e medir o mercado (sensing and sizing) - alude às origens schumpeterianas da vantagem competitiva, que pode ser considerada uma conseqüência de inovações singulares.

De acordo com Schumpeter (1957), a inovação gera lucros excepcionais - uma renda, no sentido ricardiano - cuja manutenção/renovação depende da capacidade de introduzir inovações no mercado, assim perpetuando a vantagem competitiva da firma. O objetivo de qualquer estratégia - as receitas (rendas) excepcionais - decorre de ativos singulares, que são específicos da empresa e não podem ser imediatamente reproduzidos; essas rendas ricardianas, derivadas da escassez, devem-se a fatores intrinsecamente raros e valiosos, e são difíceis de obter. Assim, a VBR diferencia-se da discussão sobre o posicionamento dos produtos no mercado, voltando a deslocar o foco da análise para a empresa. No jogo competitivo, a capacidade dinâmica é a dimensão central da estratégia, mas depende da reação de outras empresas que possam imitá-la (produtos, processos, comercialização, etc.).

Margaret Peteraf (1997) estabeleceu quatro condições para a manutenção da liderança competitiva, as quais definiu como as "pedras angulares" da competência. Para que a empresa possa manter sua vantagem, é preciso que ela satisfaça algumas condições:

- seus recursos devem ser efetivamente heterogêneos;

- a concorrência prévia deve ser limitada, ou seja, os recursos podem ser adquiridos por preço inferior ao da renda que os serviços desses fatores gerarão para a empresa;

- devem existir limites à concorrência ex post, ou seja, deve ser difícil para as organizações concorrentes imitar, comprar ou reproduzir os recursos passíveis de gerar renda;

- por último, a mobilidade dos fatores deve ser imperfeita, no sentido de que o recurso seja efetivamente específico da organização e somente esta possa se apoderar da renda por ele gerada. ${ }^{21}$

\footnotetext{
${ }^{21}$ A contribuição de Peteraf representa um avanço em relação à idéia de estratégia derivada da perspectiva baseada em recursos, embora constitua uma visão mais estática, se comparada ao conceito de "capacitação dinâmica", que renova permanentemente as bases da estratégia competitiva calcada na heterogeneidade dos recursos da empresa, ou desloca em caráter permanente as fronteiras do conhecimento.
} 
Como vimos, a consideração da "capacidade dinâmica" destaca-se na discussão sobre como são geradas as receitas schumpeterianas. No contexto de uma competência schumpeteriana, entretanto, o subconjunto é especialmente importante, pois permite à empresa criar e desenvolver novos produtos, processos e rotinas, e enfrentar com eficiência as mudanças do meio ambiente (Peteraf, 1997).

\section{Conclusão}

Resumindo, cabe enfatizar os seguintes pontos:

i. Alocação de recursos. A VBR incorpora contribuições da estratégia corporativa para explicar como são geradas as rendas: as empresas selecionam as estratégias que melhor utilizem seus recursos. A firma compreende ou se conscientiza de sua vantagem estratégica ao avaliar sua posição como detentora de recursos (pontos fortes e pontos fracos). Suas aptidôes singulares, em termos de conhecimento tecnológico e capacidade empresarial, são fontes importantes de heterogeneidade, que podem resultar em vantagens comparativas sustentáveis.

ii. Oportunidades. Diferentes oportunidades influenciam as percepções dos empresários e a direção do processo de diversificação produtiva.

iii. Crescimento da empresa. O crescimento da empresa se dá através da diversidade produtiva: pelo desenvolvimento da base técnica, aproveitando as oportunidades oferecidas pelas áreas de comercialização, ou pelo direcionamento antecipado do processo de diversificação. Os limites penrosianos do crescimento devem-se à escassez de recursos produtivos: trabalho, recursos físicos e financeiros, falta de oportunidades de investimento, falta de capacidade empresarial. No longo prazo, o crescimento seria limitado pela falta de recursos empresariais. Essas limitações podem ser superadas através de fusões empresariais e aquisições de outras empresas.

iv. Motivação para o crescimento. A motivação para o crescimento também provém exclusivamente dos recursos da empresa. Por outro lado, a indivisibilidade do processo produtivo leva à existência de recursos ociosos, os quais, como vimos, obrigam a firma a crescer, o que geralmente acontece 
através da diversificação da produção. Em diferentes momentos, existe em cada empresa uma coletânea de serviços de recursos produtivos que lhe criam oportunidades únicas, considerando-se a perspectiva empresarial.

v. Diversidade produtiva. A diversificação das atividades com base em decisões estratégicas tende a provocar conseqüências importantes para a organização interna da empresa. Nasce uma estrutura multidepartamental que requer coordenação e cooperação com outras empresas.

vi. A abordagem evolucionária. Em linhas gerais, pode-se dizer que a abordagem evolucionária da empresa toma por modelo as firmas que buscam incessantemente introduzir mudanças na lista de produtos e processos produtivos, em resposta a alterações nas condições de seu funcionamento e à evolução das oportunidades de mercado, frente à concorrência de outras empresas. Existem regularidades no comportamento da empresa que se relacionam com sua "genética institucional" - as características reforçadoras de sua capacidade de produzir e obter lucros que são confirmadas e transmitidas ao longo do tempo (Nelson \& Winter, 1982). A idéia-chave da teoria evolucionária é o conceito de "rotina organizacional" - uma forma costumeira de fazer as coisas e uma tomada de decisões baseada na capacidade da empresa e em processos recorrentes de escolha. A rotina tem traços operacionais concernentes à atividade de investimento, à tomada de decisões estratégicas e à capacidade de a empresa modificar suas características organizacionais. Nos departamentos de P\&D, mas também em atividades sistemáticas ou assistemáticas de planejamento, podem decidir-se mudanças na orientação do crescimento da empresa. Nelson e Winter (1982) distinguem um tipo especial de rotina: as "rotinas de seleção e busca de oportunidades lucrativas". Essas rotinas podem gerar transformações posteriores no comportamento da empresa (Nelson \& Winter, 1982).

vii. Capacitação dinâmica. A teoria da capacitação dinâmica das empresas baseia-se na premissa de que as firmas cujo estudo interessa são aquelas que estão num contexto schumpeteriano de mudança tecnológica. Por conseguinte, as empresas devem ter a capacidade de gerar inovações num sentido lato, bem como de explorar os possíveis desdobramentos destas. 
A capacitação dinâmica é a capacidade de intuir e aquilatar novas oportunidades de lucro à medida que elas se apresentam, e de introduzir novas mudanças empresariais.

Em termos gerais, diríamos que as linhas ou opções estratégicas adotadas pela empresa levam em conta:

1. a dotação específica de recursos produtivos (Penrose);

2. a "competência central" (Prahalad e Hamel);

3. a capacidade de readaptação às mudanças ambientais e às exigências do consumidor, ou, melhor ainda, às mudanças institucionais (Hodgson).

4. a "capacitação dinâmica" da empresa (Teece), fundamental em épocas de mudança e demonstrada pela habilidade para "sentir e medir o mercado";

5. a possibilidade de obter "rendas diferenciais" (Peteraf), que podem provir: do quase-monopólio de determinada inovação (barreiras ex post à concorrência) ou da existência de barreiras ex ante, derivadas da capacidade de extrair mais serviços dos resultados obtidos pela empresa no mercado, seja pela heterogeneidade dos recursos, seja por sua mobilidade imperfeita (estando estes dois últimos fatores associados à renda ricardiana);

6. a capacidade de "capturar o valor do ativo representado pelo conhecimento" nas rendas diferenciais e de manter esse valor dentro da empresa (Teece, 1998), que está relacionada com os dois primeiros casos de vantagem competitiva mencionados por Peteraf (barreiras ex ante e ex post);

7. a rede de relações técnicas, produtivas, comerciais, jurídicas e de confiança estabelecida com outras empresas e com os próprios interessados na firma (stakeholders).

Por último, gostaríamos de voltar ao ponto de partida deste artigo-resenha: as abordagens institucionalista/evolucionária produzem uma visão muito diferente da que deriva do neo-institucionalismo, calcado em conceitos de racionalidade limitada, custos de transação e comportamento oportunista dos agentes. Segundo esta última hipótese, as organizações são cadeias de contratos e hierarquias em que a coordenação é uma questão de imposição das regras preexistentes. Talvez isso seja verdade, em condições institucionais 
especiais. De acordo com a hipótese evolucionária, entretanto, as organizações são entidades que aprendem, coordenadas por dispositivos diferentes "recompensa e castigo", interesses, rotinas, crenças e cooperação, para citar apenas os mais importantes. Mais do que isso, a dimensão estratégica pode ser vista como a principal explicação do crescimento da empresa e, fundamentalmente, como a expressão de sua coleção singular de recursos.

\section{Referências bibliográticas}

Barkow, J. H.; Cosmides, L. ; Tooby, J., The Adapted Mind, Evolutionary Psychology and the Generation of Culture, Oxford: Oxford University Press, 1992.

Boyer, R., "Technical Change and the Theory of Regulation", in G. Dosi. et al., Technical Change and Economic Theory, Londres: London Printer, 1988.

Castro, A. B.; Proença, A., Novas Estratégias Industriais: Sobrevida ou Inflexão?, Rio de Janeiro: FINEP, DRH, 2001.

Chandler, A. D., "Strategy and Structure", in Foss (org.), 1997.

Chang, H-J.; Evans, P., “The Role of Institutions in Economic Change”, versão revista, apresentada em The Other Canon Meeting, Oslo, 14-15, ago., 2000, texto mimeografado. A versão final será publicada em G. Dymski e S. De Paula, Re-imagining Growth, 2004.

Coase, R. H., “The Nature of the Firm”, Economica (4), p.386-405, 1937.

Commons, J. R., “Institutional Economics”, American Economic Review (21), 1931, p. 648-657.

Dymski, G.; De Paula, S., Re-imagining Growth (no prelo), 2004.

Foss, N. J. (org.), Resources, Firms and Strategies - A Reader in the Resource-based Perspective, Oxford: Oxford University Press, 1997.

Guemawat, P.; Collins, D. J.; Pisano, G. P.; Rivkin, J. W., Strategy and the Business Landscape, Nova York: Addison-Wesley, 1999.

Hodgson, G., Economics and Institutions, Londres: Polity Press, 1988.

"Institutions and Economic Development: Constraining, Enabling and Reconstituting” (2003), in G. Dymski e S. De Paula, Re-imagining Growth, no prelo, 2004. 
, "Opportunism is Not the Only Reason Why Firms Exist: Why an Explanatory Emphasis on Opportunism May Mislead Management Strategy”, in Industrial and Corporate Change, v.13, n.2, p.401-418, 2004.

King, J. E., "Value and Exploitation: Some Recent Debates", in Bradley, I.; Howard, M. (orgs.), Classical and Marxian Political Economy, Londres: Macmillan, 1982.

Liebenstein, H., X-Efficiency Theory and Economic Development, Oxford: Oxford University Press, 1978.

Loader, R., "Transaction Costs and Relations in Agrifood Systems", in Proceedings of the Second International Conference on Chain Management, Wagenngen, Holanda, 1995.

March, T. G.; Simon, H., Organizations, Oxford: Basil Blackwell, 1993.

Ménard, C., "Le pilotage des formes organisationelles hybrides", in Revue Economique, 42 (3), p.741-750, 1997.

Milgrom, P. R.; Roberts, J., Economics, Organization and Management, Nova York: Prentice-Hall International Inc., 1992.

Mintzberg, H.; Quinn, J. B., Readings in the Strategy Process, Cambridge: Prentice Hall, 1998.

Nelson, R. R., "Why do Firms Differ and How Does it Matter?”, in Foss (org.), p.257-267, 1997. ; Winter, S. G., An Evolutionary Theory of Economic Change, Cambridge: Harvard University Press, 1982.

North, D. C., Institutions, Institutional Change and Economic Performance, Cambridge: Cambridge University Press, 1990.

Penrose, E., "The Theory of the Growth of the Firm”, in Foss (org.), 1997.

Peteraf, M. A., "The Cornerstones of Competitive Advantage: A Resource-based View”, in Foss (org.), p.187-203, 1997.

Porter, M., Estratégia competitiva, Rio de Janeiro: Campus Editora, 1986.

, The Competitive Advantage of Nations, Nova York: McMillan, 1990.

Prahalad, C. K.; Hamel, G., “The Core Competence of the Corporation”, in Foss (org.), p.235256, 1997.

Schejtman, A., "Agroindustria y Pequeña Agricultura: Experiencias y Opciones de Transformación”, in Agroindustria y Pequeña Agricultura: Vinculos, Potencialidades y Oportunidades Comerciales, Santiago do Chile: 1998.

Schumpeter, J., Teoría del Desenvolvimiento Economico, Buenos Aires: Fondo de Cultura Económica, 2a ed., 1957. 
Selznick, P., "Leadership in Administration: A Sociological Interpretation”, in Foss (org.), p.2126, 1997.

Simon, H., "From Substantive to Procedural Rationality", in S. Latsis (org.), Methods and Appraisal in Economics, Cambridge: Cambridge University Press, 1976.

Smith, L. W., Reform and Decentralization of Agricultural Services: A Policy Framework, Roma: FAO, 2001.

Teece, D., “The Dynamic Capabilities of Firms: An Introduction”, in G. Dosi, D. J. Teece e J. Chytry, Technology, Organization, and Competitiveness, Perspectives on Industrial and Corporate Change, Oxford: Oxford University Press, 1998, p. 193-214.

Teubal, M., Globalización y Expansión Agroindustrial. ¿Superación de la Pobreza en América Latina?, Buenos Aires: Ed. Corregidor, 1995.

Veblen, T. B., The Place of Science in Modern Civilization and Other Essays, Nova York: Huebsch, 1919; reeditado com nova introdução de W. J. Samuels, New Brunswick, NJ: Transaction, 1990.

Williamson, O. E., The Economic Institutions of Capitalism, Nova York: Free Press, 1985.

Zylbersztajn, D., "Governance Structures and Agribusiness Coordination: A Transaction Cost Economics Based Approach", in Research in Domestic and International Agribusiness Management, 12, 1996, p. 245-310.

; Fava Neves, M., Economia das Organizaçôes, São Paulo: Campus Editora, 2000. 


\section{Estudos de caso que trazem exemplos práticos de várias abordagens teóricas da análise dos sistemas agroalimentares}

Almeida, L. S.; Piedade, M. A., "Estrutura, conduta e desempenho da cadeia avícola brasileira", in X World Congress of Rural Sociology/XXXVIII Congresso Brasileiro de Economia e Sociologia Rural, Rio de Janeiro, 30 de julho a 5 de agosto de 2000 (CD-Rom).

Besada, A. F; Formento, S., "Estrategias para Pequeños y Medios Productores en un Ambiente Competitivo: Un Estudio de Caso de Integración Vertical en el Sector Avícola Argentino", in X World Congress of Rural Sociology/XXXVIII Congresso Brasileiro de Economia e Sociologia Rural, Rio de Janeiro, 30 de julho a 5 de agosto de 2000 (CD-Rom).

Ferreira, N. C. M.; Callado, A. A. C., "A Vantagem Competitiva em Empresas Rurais”, in X World Congress of Rural Sociology/XXXVIII Congresso Brasileiro de Economia e Sociologia Rural, Rio de Janeiro, 30 de julho a 5 de agosto de 2000 (CD-Rom).

FGV/EMBRAPA, Cadeias produtivas no Brasil. Análise da competitividade, editores técnicos: Rita de Cássia Milagres Teixeira Vieira, Antônio Raphael Teixeira Filho, Antônio Jorge de Oliveira, Mauro Resende Lopes. Ministério da Agricultura e do Abastecimento, Brasília, DF, 2001 (estudo de caso 4.3).

Minozzo, A. R.; Shikida, P. F. A., "A Dinâmica Tecnológica da Agroindústria Leiteira no Brasil e no estado do Paraná: uma Perspectiva Neo-Schumpeteriana”, in X World Congress of Rural Sociology/XXXVIII Congresso Brasileiro de Economia e Sociologia Rural, Rio de Janeiro, 30 de julho a 5 de agosto de 2000 (CD-Rom).

Pigatto, G.; Meireles de Souza, H., "Ambiente Institucional e Indústria de Carne Bovina no Brasil”, in II Seminário Brasileiro da Nova Economia Institucional, Campinas, Unicamp, março de 2001 (CD-Rom).

Scarlatto, G., "Trayectoria y demandas tecnológicas de las cadenas agroindustriales en el Mercosur ampliado. Cereales: trigo, maíz y arroz", in PROCISUR/BID, 2000.

Zanatta, M. C., Contribuciones teóricas recientes al estudio de estrategias empresariales, Rio de Janeiro: CPDA/UFRRJ, 2001 (texto mimeografado)

Zylbersztajn, D.; Machado Filho, C. P., Competitividad de la cadena agroindustrial de la carne en Brasily extensiones para América Latina, São Paulo: USP, 2000 (texto mimeografado). 